\title{
ESTUDO DA ESTABILIDADE FÍSICO-QUÍMICA E QUÍMICA DO SUCO DE CAJU COM ALTO TEOR DE POLPA ${ }^{1}$
}

\author{
Geraldo Arraes MAIA ${ }^{2, *}$, José Carlos Sabino MONTEIRO², \\ Antonio Cláudio Lima GUIMARÃES²
}

\begin{abstract}
RESUMO
Obteve-se o suco de caju com alto teor de polpa utilizando-se o processo combinado de tratamento térmico e conservantes químicos. Utilizaram-se vários teores de metabissulfito de sódio e nitrogênio, estudando-se em seguida, a estabilidade dos produtos obtidos. Verificou-se que o suco tratado com nitrogênio e $300 \mathrm{ppm}$ de $\mathrm{SO}_{2}$ apresentou melhor qualidade no que se refere principalmente à cor, quando comparado àquele tratado somente com nitrogênio.
\end{abstract}

Palavras-chave: suco; metabissulfito de sódio; nitrogênio; vidade-prateleira.

\section{SUMMARY}

PHYSICO-CHEMICAL AND CHEMICAL STABILITY OF HIGH PULP CASHEW APPLE JUICE. Cashew apple juice was obtained by a combined process using heat treatment and chemical preservatives. Several concentrations of $\mathrm{SO}_{2}$ were used combined with nitrogen stripping. It was found that the juice treated with $300 \mathrm{ppm}$ of $\mathrm{SO}_{2}$ combined with nitrogen presented the best quality with regard to color when compared to the one treated only with nitrogen.

Key words: juice; sodium metabissulfite; nitrogen; shelf life.

\section{1 - INTRODUÇÃO}

$\mathrm{O}$ cajueiro (Anacardium occidentale L.) pertence à família Anacardiaceae e é considerado uma das culturas de maior importância econômica do Nordeste, sendo cultivado principalmente nos Estados do Ceará (68\%), Rio Grande do Norte (11\%) e Piauí (8\%) [3].

Os produtos da castanha: amêndoa e LCC (Líquido da Castanha de Caju) e os derivados do pedúnculo, principalmente, o "suco de caju alto teor de polpa," assumem elevada importância econômica, dando margem ao estabelecimento de grandes unidades industriais, com capacidade de 20 toneladas de pedúnculo por hora, nas regiões produtoras [6].

O Brasil como destacado produtor mundial de frutas frescas, luta em várias frentes para expandir o incipiente mercado de sucos tropicais, consciente do potencial econômico que encerra e, da importância que tem esse mercado para o desenvolvimento da própria fruticultura nacional [4].

São reconhecidos dois períodos que caracterizam a evolução da agroindústria do caju. O primeiro, exis-

${ }_{1}^{1}$ Recebido para publicação em 28/03/00. Aceito para publicação em 18/04/01.

${ }^{2}$ Universidade Federal do Ceará - Departamento de Tecnologia de Alimentos, Cx. Postal 12168, CEP60356-000, Ce. frutos@ufc.br.

${ }^{*}$ A quem a correspondência deve ser enviada. tente desde os primórdios da colonização, caracterizava-se por ser extrativista. Esse sistema subsiste nos dias atuais e responde por parcela significativa de castanha, que entra no circuito de comercialização [9]. $O$ segundo período, iniciado em meados da década de sessenta, caracterizou-se por uma considerável expansão dos setores agrícola e industrial. O mercado favorável para os produtores do caju, a existência de incentivos fiscais e subsídios oferecidos aos produtores industriais, e, o fato de serem produtos geradores de divisas necessárias à consolidação do modelo exportador, foram responsáveis pela acelerada expansão agroindustrial do caju. A escassez da matéria-prima, decorrente da elevação de preços da castanha, concorreu para que os empresários do setor, também investissem em programas de plantio, visando o abastecimento de suas indústrias [2].

A agroindústria do caju representa nos dias atuais parcela significativa da economia do Nordeste do Brasil, em decorrência dos produtos industrializados oriundos do seu fruto e pseudofruto. O parque industrial ligado a este setor da economia é constituído de 23 indústrias de beneficiamento do fruto (castanha) e 8 indústrias voltadas para o aproveitamento do pseudofruto [2]. A agroindústria do caju é responsável no Nordeste por uma área plantada em torno de 1 milhão de hectares, gerando mão-de-obra direta e indireta no segmento agrícola, industrial e de serviços para 1,5 milhão de pessoas. Deve-se ressaltar que a referida cultura está se expandindo por todo o Brasil.

Em vista desses aspectos, o presente trabalho teve por objetivo, estudar a estabilidade físico-química e química do "suco de caju alto teor de polpa", verificando-se a influência do uso de baixo teor de $\mathrm{SO}_{2}$ na conservação do suco.

\section{2 - MATERIAL E METÓDOS}

A matéria-prima utilizada consistiu de frutos da espécie Anacardium occidentale L., coletados no Município de Pacajus-Ceará, com coordenadas geográficas compreendendo latitude de $4^{\circ} 19^{\prime} \mathrm{S}$, longitude $38^{\circ} 19^{\prime} \mathrm{N}$ e altitude de $42 \mathrm{~m}$. As precipitações médias no município, no decorrer dos últimos 50 anos, apresentaram média de $794,1 \mathrm{~mm}$, com um mínimo de $232,1 \mathrm{~mm}$ e máxima de $1.382,1 \mathrm{~mm}$.

Os cajus foram colhidos manualmente, evitandose, os descastanhados, sendo os pedúnculos acondicionados em caixas plásticas, que foram transportadas por via terrestre para a unidade de processamento, onde foram recebidos e pesados. Os pedúnculos foram la- 
vados em água corrente e selecionados em esteiras de seleção, com a eliminação das unidades defeituosas. O material selecionado foi desintegrado, ocasião em que houve uma injeção de vapor, conduzido à despolpadeira, onde se obteve o suco e as fibras. $O$ suco refinado foi bombeado ao tanque de formulação, onde adicionou-se conservantes em quantidades de 200ppm e 300ppm de $\mathrm{SO}_{2}$, benzoato de sódio (500ppm) e ácido cítrico ( $\mathrm{pH}$ até 3,5$)$. O produto assim formulado foi desaerado com o objetivo de remover o oxigênio, homogeneizado à pressão de 100atm, pasteurizado em pasteurizador de tubos paralelos, a $90^{\circ} \mathrm{C}$ por 60 segundos, seguindo-se o enchimento à quente, em garrafas de capacidade para $500 \mathrm{ml}$. O nitrogênio foi fornecido pela White Martins S/A e utilizou-se a técnica de "stripping" que consiste na injeção do gás na tubulação que conduz o suco, antes do enchimento, numa vazão de 230 litros/hora, senda esta, o dobro da vazão do suco. As garrafas foram, então, fechadas com cápsulas metálicas, com proteção plástica, resfriadas em água corrente em resfriador contínuo de esteira, rotuladas, acondicionadas em caixas de papelão com capacidade para 24 garrafas, e armazenadas à temperatura ambiente $\left(28^{\circ} \mathrm{C}\right)$.

O "Suco de Caju alto teor de polpa" e com baixo teor de $\mathrm{SO}_{2}$ foi obtido conforme o descrito no fluxograma da Figura 1.

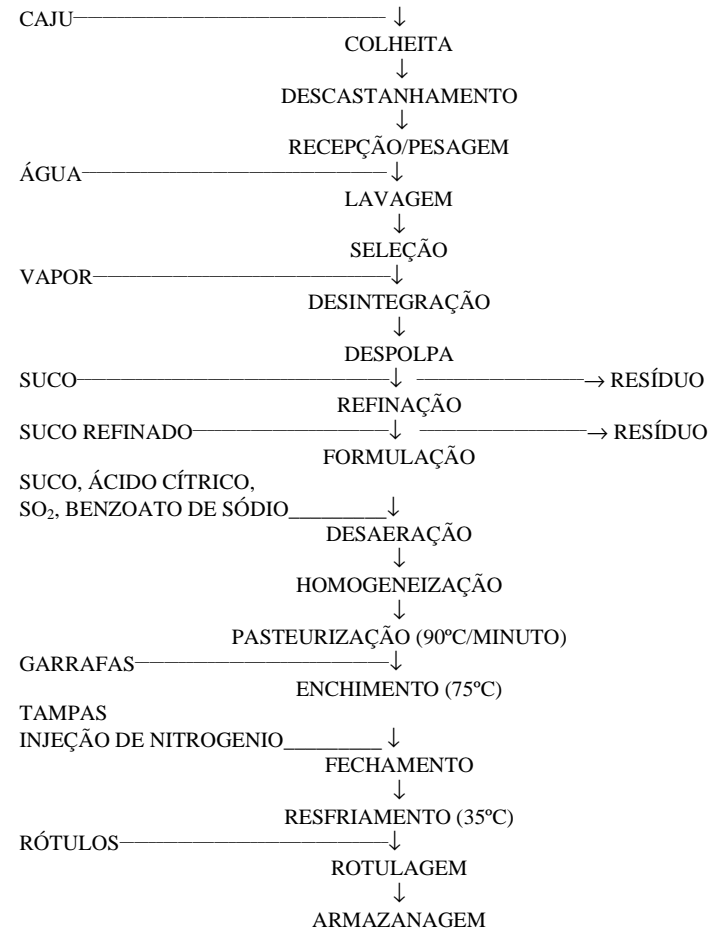

FIGURA 1. Fluxogramas das operações seguidas para obtenção do "suco de caju alto teor de polpa".

O suco obtido foi submetido a análises físico-químicas e químicas após o processamento e em intervalos de 30 dias, por um período de 360 dias.
Foram realizadas determinações no suco, consistindo de: Acidez total titulável, determinada de acordo com método descrito pelo INSTITUTO ADOLFO LUTZ [6]. $\mathrm{O} \mathrm{pH}$ foi determinado utilizando-se potenciômetro. O teor de polpa foi obtido por centrifugação. Os sólidos solúveis foram determinados em refratômetro. As determinações de açúcares redutores, não redutores e totais foram feitas de acordo com o INSTITUTO ADOLFO LUTZ [6]. O teor de ácido ascórbico foi determinado pelo método colorimétrico (2,6-diclorofenolindofenol) descrito por PEARSON [10]. $\mathrm{O} \mathrm{SO}_{2}$ foi obtido pelo método oficial adotado pelo Ministério da Agricultura e a cor por método descrito por MAIA [7].

\section{3 - RESULTADOS E DISCUSSÃO}

As Tabelas 1, 2 e 3 reúnem os resultados das análises físico-químicas e químicas do "suco de caju alto teor de polpa", com baixo teor de $\mathrm{SO}_{2}$ e sob atmosfera de nitrogênio, realizadas durante a armazenagem, para estudo de estabilidade desse produto. Estas análises são importantes, por serem em sua maioria utilizadas nos padrões de identidade e qualidade dos sucos.

Comparando-se os resultados nota-se que o suco processado somente com injeção de nitrogênio, sem adição de $\mathrm{SO}_{2}$, mostrou escurecimento mais acentuado e maior perda de ácido ascórbico, indicando nestes testes ao nível industrial, que somente a adição de nitrogênio é insuficiente para evitar o escurecimento do suco. O escurecimento é evidenciado quando compara-se os resultados obtidos da determinação de pigmentos solúveis em água.

Os resultados referentes a perda de ácido ascórbico no decorrer do armazenamento são semelhantes aos obtidos por outros pesquisadores $[1,5,8]$.

Observa-se que praticamente não houve variação nos valores de ${ }^{\circ}$ Brix, Açúcares, $\mathrm{pH}$ e Acidez, indicando uma perfeita estabilidade do produto durante o armazenamento. Os resultados deste trabalho são de importância para a indústria de suco de caju e para os órgãos governamentais que legislam sobre alimentos, uma vez que mostra que o teor de 300ppm de $\mathrm{SO}_{2}$ é o mais seguro para obtenção de um produto de qualidade.

O melhor resultado observado para o período de armazenagem foi aquele apresentado quando o suco foi tratado com 300ppm de $\mathrm{SO}_{2}$ e com adição de nitrogênio, o que foi evidenciado pelo menor grau de escurecimento e maior retenção de vitamina $\mathrm{C}$. O suco tratado com 200ppm de $\mathrm{SO}_{2}$ e atmosfera de nitrogênio apresentou escurecimento mais pronunciado que o tratado com 300ppm. Em todos os casos nota-se que houve um decréscimo constante no teor de $\mathrm{SO}_{2}$ para todos os tratamentos, bem como uma queda nos teores de vitamina $\mathrm{C}$.

Com a tecnologia atualmente utilizada, é muito difícil evitar escurecimento do suco de caju, quando tratado com teores de $\mathrm{SO}_{2}$ abaixo de 400ppm, que é bastante razoável, visto a diluição para consumo ser de 10 vezes. 
TABELA 1. Características Físico-químicas e Químicas do "Suco de Caju alto teor de polpa" sem adição de $\mathrm{SO}_{2}$ e $\mathrm{com}$ adição de Nitrogênio

\begin{tabular}{|c|c|c|c|c|c|c|c|c|c|c|c|c|c|}
\hline Determinações & \multicolumn{13}{|c|}{ Tempo de Armazenagem (dias) } \\
\hline $\mathrm{pH}$ & 4,12 & 4,10 & 4,05 & 3,90 & 3,90 & 3,90 & 3,90 & 3,90 & 4,00 & 3,90 & 3,95 & 3,85 & 4,00 \\
\hline Açúcares redutores (\%) & 9,30 & 9,31 & 9,35 & 9,35 & 9,37 & 9,30 & 9,30 & 9,35 & 9,36 & 9,40 & 9,30 & 9,35 & 9,35 \\
\hline Açúcares não redutores (\%) & 0,25 & 0,24 & 0,25 & 0,23 & 0,25 & 0,29 & 0,25 & 0,26 & 0,23 & 0,24 & 0,25 & 0,26 & 0,26 \\
\hline Açúcares totais (\%) & 9,55 & 9,55 & 9,60 & 9,58 & 9,62 & 9,59 & 9,55 & 9,61 & 9,59 & 9,64 & 9,55 & 9,61 & 9,61 \\
\hline
\end{tabular}

TABELA 2. Características Físico-Químicas e Químicas do "Suco de Caju alto teor de polpa " com 200ppm de $\mathrm{SO}_{2}$ e com injeção de Nitrogênio

\begin{tabular}{|c|c|c|c|c|c|c|c|c|c|c|c|c|}
\hline Determinações & \multicolumn{12}{|c|}{ Tempo de Armazenagem (dias) } \\
\hline $\mathrm{pH}$ & 4,00 & 3,75 & 3,60 & 3,50 & 3,70 & 3,80 & 3,70 & 3,60 & 3,75 & 3,80 & 3,80 & 3,75 \\
\hline Açúcares redutores (\%) & 9,60 & 9,56 & 9,45 & 9,56 & 9,60 & 9,50 & 9,45 & 9,58 & 9,48 & 9,60 & 9,50 & 9,45 \\
\hline Açúcares não redutores(\%) & 0,26 & 0,26 & 0,28 & 0,22 & 0,24 & 0,27 & 0,26 & 0,28 & 0,28 & 0,27 & 0,29 & 0,28 \\
\hline Açúcares totais (\%) & 9,86 & 9,82 & 9,73 & 9,78 & 9,84 & 9,77 & 9,71 & 9,86 & 9,76 & 9,87 & 9,79 & 9,73 \\
\hline \multicolumn{13}{|l|}{ (Absorbância 420nm) } \\
\hline $\mathrm{SO}_{2}$ & 190,0 & 160,0 & 147,0 & 120,0 & 100,0 & 92,0 & 75,0 & 68,0 & 57,0 & 42,0 & 38,0 & 25,0 \\
\hline
\end{tabular}

TABELA 3. Características Físico-Químicas do "Suco de Caju alto teor de polpa" com 300 ppm de $\mathrm{SO}_{2}$ e com adição de Nitrogênio

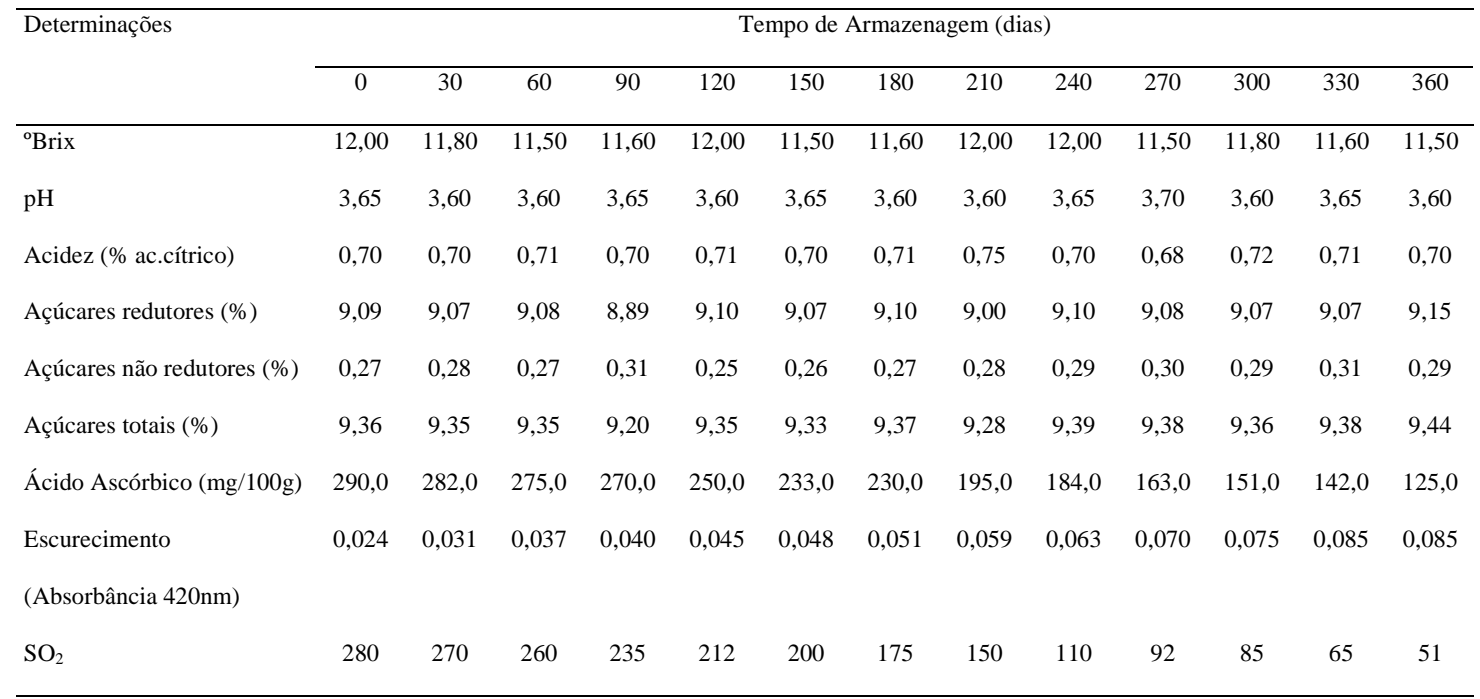


Os estudos sobre o efeito combinado do nitrogênio e metabissulfito no suco devem ser continuados inclusive em várias indústrias produtoras, para que se possa utilizar os teores mínimos de $\mathrm{SO}_{2}$, que situam-se na faixa de 200ppm.

Algumas recomendações podem ser oferecidas com base nos resultados obtidos, quais sejam: a matériaprima deverá apresentar maturação uniforme, ausência de sujeiras, fungos; cuidados na colheita e transporte evitando a danificação; processar o mais rápido possível a matéria-prima (no máximo até $5 \mathrm{~h}$ ). Estes cuidados são essenciais, porque quanto menor a danificação dos pedúnculos menor será a intensidade de escurecimento do produto final e menor quantidade de $\mathrm{SO}_{2}$ a ser utilizada.

\section{4 - CONCLUSÕES}

- Quanto a conservação, todos os tratamentos foram adequados, visto não haver alteração significativa no decorrer da armazenagem no que se refere às características físico-químicas. $O$ escurecimento tornou-se evidente visualmente no segundo mês de armazenagem para todos os tratamentos.

- Os estudos sobre o efeito combinado do nitrogênio e metabissulfito de sódio no suco de caju, mostraram que a concentração de $300 \mathrm{ppm}$ de $\mathrm{SO}_{2}$ foi a mais efetiva na preserveção da cor e do teor de ácido ascórbico.

- Os demais parâmetros analizados pH, Brix, acidez total e açúcares não mostraram alteração importante do ponto de vista industrial.

\section{5 - REFERÊNCIAS BIBLIOGRÁFICAS}

[1] CAVALCANTE, M.A.; MAIA, G.A.; ORIÁ, H.F.; FIGUEIREDO, R.W.; GUEDES, Z.B.L. Estudo do processamento e estabilidade da cajuína a partir do suco de caju (Anacardium occidentale L.). Ciên, Agron., Fortaleza, v. 17, n. 1, p. 105-109, 1986.

[2] EMBRAPA - Empresa Brasileira de Pesquisa Agropecuária. A indústria do caju - sua importância no Brasil e no mundo. Brasília, EMBRAPA, 1983, 42 p. (Mimeografado).

[3] EMBRAPA - Empresa Brasileira de Pesquisa Agropecuária. Campanha nacional de aumento da produtividade do cajueiro e produtos derivados do cajueiro. Fortaleza, 1992, 4p.

[4] FRANÇA, F.M.C. Produção, comercialização e mercado. In: LIMA, V. de P.M.S. A cultura do cajueiro no Nordeste do Brasil. Fortaleza, Banco do Nordeste do Brasil, 1988. p. 63-80.

[5] HOLANDA, L.F.F.; FÉ, J.A.M.; MARTINS, C.B.; MAIA, G.A. Resultados preliminares sobre a estabilidade do doce de caju em calda. Ciên. Agron., Fortaleza, v.5, n.1-2, p.7981, 1975.

[6] INSTITUTO ADOLFO LUTZ. Normas Analíticas do Instituto Adolfo Lutz; métodos físicos e químicos para análise de alimentos. 3ª edição.I.A.L., São Paulo, vol. I., p. 124 e $141,1985$.

[7] MAIA, G.A.; HOLANDA, L.F.F. ; MARTINS, C.B. Características físicas e químicas do Caju (Anacardium occidentale, L.). Ciên. Agron., Fortaleza, v. I, n. 2, p. 115-120, 1971.

[8] MAIA, G.A.; SOARES, J.B. Gradientes de acidez, açúcares e ácido ascórbico no caju. Bol. Cear. Agron., Fortaleza, v.11, p.25-29, 1970.

[9] PARENTE, J.I.G.; PESSOA, P.F.A.P.; NAMEKATA, Y. Diretrizes para recuperação da Cajucultura no Nordeste. Documento no 04, EMBRAPA. Março 1991.

[10] PEARSON, D. Laboratory Techniques in Food Analysis. London. Cox \& Pearson, 1975. 